\title{
Company Comparison: General Motor Corporation VS Geely Auto
}

\author{
Zijian Ding ${ }^{*}$, Baocheng Duan ${ }^{2}$, Shuo Fang ${ }^{3}$, and Mengyang Wang ${ }^{4}$ \\ ${ }^{1}$ Dulwich International High School Suzhou, Suzhou, 215021, China \\ ${ }^{2}$ Cambridge School of Weston, Weston, 02453, US \\ ${ }^{3}$ Dulwich International High School Suzhou, Suzhou, 215021, China \\ ${ }^{4}$ Zhengzhou Foreign Language School, Zhengzhou, 450000, China \\ *Corresponding author.Email: 3116939363@qq.com
}

\begin{abstract}
Car industries are growing in size in recent years, more new entrants are entering this market seeking for profit. However, only a few firms succeed. This paper, we determine the reasons for the success of the two companies--General Motors Corporation (GM) and Geely Auto. We firstly analysed the business models for two firms, according to the business model, we firstly applied Peter Thiel's seven questions to comprise the differences in product innovation between the two firms. Then we compared consumer preference, infrastructure, and government regulations between China and the US, which is also based on the two firms' business models. The main reason for their success was they both targeted the right consumers and they follows government' favorable policies. This work could provide new entrants in the car market with some ideas about how to success in the car market and offer them an insight of two sample business models developed by GM and Geely.
\end{abstract}

Keywords: Business comparison, Business Model, Peter Thiel's seven questions, Start-up

\section{INTRODUCTION}

GM (founded in 1908) is an American automobile company founded by William Durant. It includes many subsidiary companies such as Buick, Chevrolet, and Cadillac. Geely (founded in 1986) is a Chinese automobile company founded by Li Shufu. Before producing any cars in 1998, it manufactured fridges and motorcycles. Today, both companies are top on the automobile market. Their success are heavily dependent on their values created and timing.

\section{BUSINESS MODEL COMPARISON}

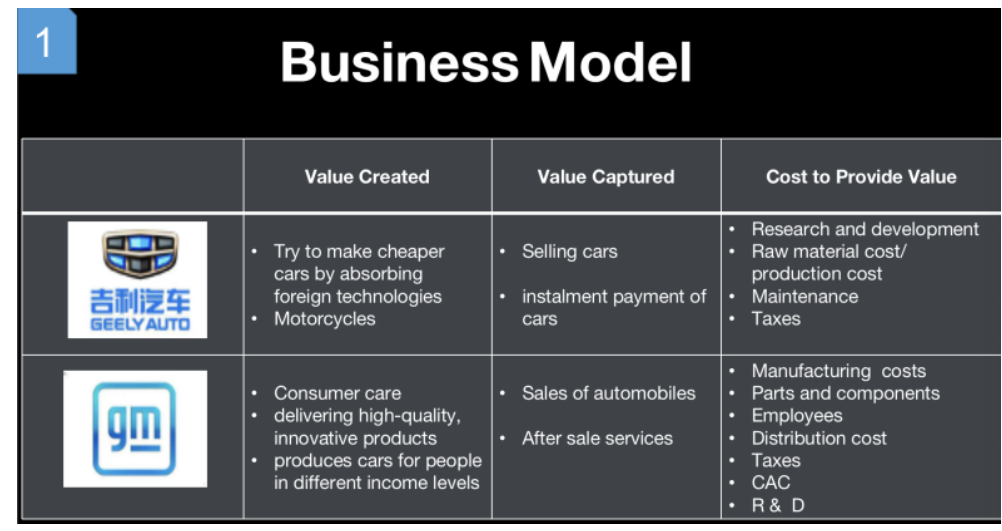

Figure 1. Business model for GM and Geely

Figure 1 shows that the value created by Geely was to build cars at a low cost, while GM mainly focus on the high innovation and quality. The value captured by
Geely was simply selling cars, but GM provided after sale services as well. Moreover, the cost to provide value for Geely was to buy engines from other 
countries, while GM spent most of its money on R \& D.

\subsection{Innovation comparison:}

In order to analyze how GM and Geely Auto did their product innovation in their early stage and how these innovations help them, Peter Thiel's seven questions are an excellent way to do the analysis.

\subsubsection{General Motors Corporation:}

\subsubsection{The Engineering Question: Can you create breakthrough technology instead of incremental improvements?}

1908, the year GM started their business to 1925 , GM spent much money doing research and innovation.

There were two main innovations that GM's engineer did.

a.Delco system in 1912 (Vaughan) [1]

b.Lacquer paint system in 1920 (Tsien) [2]

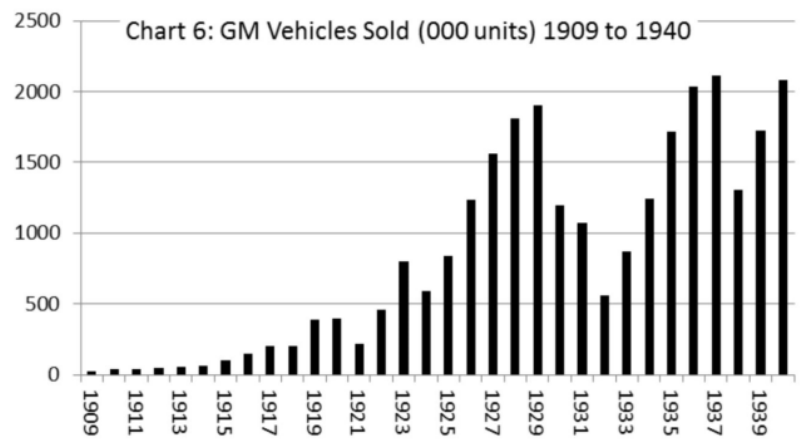

Figure 2. GM Vehicles sales

a.The Delco system was used in electric starting and lighting in 1912, and this system was more straightforward, smaller, and more practical than previous efforts. Cadillac was the first division to use the Delco system in their cars. (Vaughan) As shown on Figure 2, in 1911, GM vehicles sold (000 units) was about 3.3. After introducing the Delco system in 1912, the sales of GM vehicles has been increasing gradually. (Maielli, Colin) [3] However, the annual increase in sales was small, which means the introduction of the Delco system was not that successful.

b.In 1920, GM's engineers made the first successful Lacquer paint system for cars. This system cut the production cost from fifteen days to less than one day. (Tsien) As a result of the cut in production time, the average cost per car was reduced. This should give GM a competitive advantage. However, the depression during 1920 and 1921 in the US raised the unemployment rate from $4 \%$ to nearly $12 \%$ and made the GDP drop by 17\%. (Woods) [4]. This depression reduced the disposable income for the US citizens at that time, so the demand for cars dropped, given that cars are a kind of luxury goods. In 1921, the sales of GM cars declined about 50\% compared to that in 1920 .
(Maielli, Colin)

\subsubsection{The Timing Question: Is now the right time to start your particular business?}

Although the competition in the automobile industry was severe since there were 253 active automobile manufacturers in the US in 1908 (The pit boss) [5], the GDP per capita in the US in 1900 was ranked the third (4096 USD) among all other countries, other European countries' GDP per capita such as Germany (3134 USD) and France (2849 USD) are significantly lower than the US. (NationMaster) [6].

This shows that people in the US had enough money to purchase cars, so this could be a perfect time to start the business.

\subsubsection{The Monopoly Question: Are you starting with a big share of a small. market?}

In 1908, when GM first started their business, they only owned Buick, and the dominant firm was FM. Table 1 shows the production figures in 1908 in the US. (James) [7] 
Table 1. Car production figures in 1908

\begin{tabular}{|l|l|}
\hline Ford & 10,202 \\
\hline Buick & 8820 \\
\hline Studebaker & 8132 \\
\hline Maxwell & 4455 \\
\hline REO Motor Car Company & 4105 \\
\hline Rambler & 3597 \\
\hline Cadillac & 2377 \\
\hline Franklin & 1895 \\
\hline Total & 43583 \\
\hline
\end{tabular}

The market share of Buick is calculated by $8820 / 43583=20 \%$, and the total number of productions were relatively small compared to other manufactured goods. So, we can conclude that GM started in a small market, but their market share was not very small.

\subsubsection{The People Question: Do you have the right team?}

William Crapo Durant. The owner of GM decided to purchase Cadillac for \$5.5 million on July 29, 1909. Henry M. Leland and his son, Wilfred, were invited to continue operating Cadillac. Also, a half interest in Oakland Motor Car Co. on January 20, 1909, was purchased by Durant. When its founder, Edward Murphy, passed away, his company came under the complete control of General Motors. (MyAutoWorld) [8] All these purchases contributed to the success of GM in 1910 and built a strong foundation for the future development of GM.

Charles Kettering was the engineer who developed electric starting and lighting using a Delco system (Vaughan). The effect of this innovation has been mentioned in question 1 , part a.

\subsubsection{The Distribution Question: Do you have a way not just to create but deliver your product?}

Yes, Cars made by GM were delivered to dealerships by trucks. The main way for GM to distribute their cars is by dealerships around the US. Chevrolet was the most important subsidiary for GM at that time, GM put most of its resources to promote Chevrolet cars and there are 10 Chevrolet car dealerships in the US before 1920 (media.gm.com)

\subsubsection{The Durability Question: Will your market position be defensible 10 and 20 years into the future?}

During the first ten years of the startup stage of GM, it is just a competitor in the market, and the market is highly competitive. By comparing GM and Ford Motor
Company (FM). GM was disadvantaged by FM in 1915 , and FM became the dominant firm at that time, so the market position was not defensible. This view could be justified by looking at the market shares of the two firms. In 1910, GM owned $22 \%$ of the market, but soon in 1915 , the market share declined to only $5 \%$ (Hayward) [9]. In 1908, when GM started their business, FM only owned $9.4 \%$ of the market, but in 1914, the Ford Motor Company's market share was $48 \%$. This increase in the market share was due to the introduction of Model T. Model T helped FM gain a competitive advantage over GM. (White) [10]

\subsubsection{The Secret Question: Have you identified a unique opportunity that others do not see?}

After the successful introduction of Model T, FM produced $60 \%$ of all the cars manufactured in the US, but all the Model Ts that FM offered are all in one colour, which was black. Alfred Sloan, Pierre Du Pont and other GM executives placed a series of virtual bets on what American consumers wanted (different makes, models and prices; cars that were status symbols and identity holders). This was a unique opportunity that GM spotted. After GM's action, in the 1930s, GM's market share had risen to $42 \%$ while Ford's had fallen to $21 \%$. This indicates that this action had won the consumers from Ford and gained a competitive advantage. (Austin) [11]

\subsubsection{Geely Auto:}

\subsubsection{The Engineering Question: Can you create breakthrough technology instead of incremental improvements?}

Geely was not innovative in the beginning. For instance, HaoQing was first built in 1998 with copies of the popular Xiali by Tianjin-FAW, a licensed copy of the Daihatsu Charade G100. Because the business model of Geely was to absorb foreign technologies, HaoQing's engine was merely an incremental improvement to that of the Charade. (Maar) [12] 


\subsubsection{The Timing Question: Is now the right time to start your particular business?}

GDP of China 1990 was 360.9 billion USD (Place Explorer) [13]

\subsubsection{The Monopoly Question: Are you starting with a big share of a small market?}

No. It had a market share of $3.44 \%$ in 2003. (Bart) [14]

\subsubsection{The People Question: Do you have the right team?}

Yes. Li Shutong, who is the brother of Li Shufu, we had to mention the predecessor of Shanghai Huapu automobile "Shanghai jieshida group". Li Shutong, who started his business in Shanghai, in May 2000, established Shanghai jieshida group to enter the field of domestic cars. However, because of the lack of production qualification, Li Shutong developed and produced cars with the help of Meilu car production license of Jiangbei Machinery Factory (duowei) [15]

\subsubsection{The Distribution Question: Do you have a way not just to create but deliver your product?}

By trucks

\subsubsection{The Durability Question: Will your market position be defensible 10 and 20 years into the future?}

In 2018, which was 20 years after HaoQing was developed, Geely Auto Group had reported the sales of 1,500,838 units per year, increasing $20.3 \%$ from last year. This year, Geely Auto had gone beyond 1.5 million sale units, keeping its position as the best-selling Chinese auto brand for passenger cars. (Chan) [16]

\subsubsection{The Secret Question: Have you identified a unique opportunity that others do not see?}

Geely had applied a patent of an invention in 2006, which was a tire monitoring system: it comprises a remote monitoring unit in the tire, a central controller, a speech indicating unit, and a brake deceleration mechanism. At the time, Geely was the first company that applied for this patent. Therefore, this patent was considered as a unique opportunity that other Chinese automobile companies did not see. (Zhejiang Geely Holding Group Co.) [17]

\subsubsection{Final Innovation comparison}

Geely was not very innovative. In the very beginning, Lishufu, who was the boss of Geely, bought a Daihatsu Charade car and imitate its engine. $\mathrm{He}$ dismentled those cars and did research on them. Later he combined parts of other cars together and built the first car in his company. Around 1999, Geely had developed a brand new engine, something similar to the four cylinder design of the Toyota. On the other hand, GM was highly innovative compared to Geely. The cost of production of production of Geely was mainly the cost to buy foreign cars, while that of GM was mostly produced by $\mathrm{R} \& \mathrm{D}$ sector.

\subsection{Infrastructure comparison:}

\subsubsection{Geely Auto:}

China's gradual improvement in the hard infrastructure since the late 1970 had paved the way for the high demand of automobiles for Geely. For the sake of urbanization after the economic reform in 1978, the Chinese government had lengthened many hard infrastructures. From 1978 to 2013, the road network had extended from 0.9 to 4.4 million kilometers, which boosted the potential for the car market in China ( $\mathrm{Li}$ ) [18]. However, these improvements may not have such an significant impact on Geely: its first car in 1998 HaoQing - was so unsuccessful that it ceased to produce by the year 2004 regardless of all the infrastructural advancement above." (De Feijter) [19]. Therefore, improvements in infrastructures had only helped Geely to a certain extent.

\subsubsection{GM:}

The late nineteen century was the golden age of the great development of American economy. And the rapid expansion of industry made the United States develop fast. The growth of the roads in the United States helped the automobile industry flourish, and the construction of highways provides the basis running for cars. By 1980, the length of public highways in the United States reached 3,859,837 mileages (Federal Highway Administration) [20]. Also, the railways and oil play important roles in the development of the automobile industry. The expansion of the market was stimulated by the development of railways, and larger market could help more people to buy cars. By 1908, American had 333.6 thousands of miles of railroad (NBER Macrohistory Database) [21]. And the United States had some of the largest reserves in the world.

\subsubsection{Final infrastructure Comparison:}

The infrastructures of both nations were developing, which built a potential market for automobiles. Specifically, both had extended the length of highways, but both had also focused on the infrastructures of oil and railway to further the expansion of the market. 


\subsection{Regulation comparison:}

\subsubsection{GM:}

American taxes on cars were lower than those in the rest of the world, especially at the purchase stage, and were mainly levied on fuel. Though there were antitrust laws to stop monopolistic acts, such as buying companies, in after 1890 "American courts soon began struggling with the Act's broad and vague language, recognizing that interpreting it literally might make even simple business entities like partnerships illegal." (Chen) [22]. As a result, the government had very little interest in controling GM from buying other companies, leading more market share.

\subsubsection{Geely Auto:}

The Chinese government did not limit the development of Geely, but instead, these regulations on the automobiles had actually boosted it. Before China had joined the World Trade Organization (WTO) in 2001, the government had tried to limit the amount of imported cars by tariffs, which was 260 percent import duty on directly imported automobiles. However, since international tourism was opened in the early 1980, the demand of taxies and privately owned cars had sharply increased. The Chinese government had largely supported joint ventured product between domestic and oversea producers with a much lower tariff (Harwit) [23]. The true intention of this policies was to allow Chinese car companies to work and learn the technologies of the foregin automobiles (Ma) [24]. For Geely, according to its business model, it meant the company could have a cheaper way to access foreign technologies, which directly benefited Geely. In fact, knowing the Chinese government supported investment of foreign technologies, it even bought Volvo Cars Corporation from Ford Automotive in 2010. (Geely Russia) [25].

\subsubsection{Final Regulation Comparison:}

The main similarity for both firms was Protectionism methods used by the two governments to help their infant industry -- car industry to grow. The Chinese government leived some tarriffs on imported cars to prevent foreign competition while the US government lowered the taxes on fuels to encourage car consumption. Desipte the similarity mentioned above, there was still a difference: the Chinese government encouraged domestic car companies to collabroate with foreign firms to integrate into some joint ventures, but the US government did not do that.

\subsection{Consumer Preferences Comparison:}

\subsubsection{GM:}

During the startup period, GM found that most consumers considered cars as status symbols or identity holders. (Austin). As a result, their target consumers should be the rich. Fashionable designs could attract wealthy people to purchase their car, so GM's value created was to provide high quality and innovative products. Moreover, due to the invention of light bulbs and telephones, the living standard for people increased. People were demanding innovative products such as state of the art cars to commute transportation to improve their quality of life. As a result, the demand for cars increased, which means there was a trend towards people switching from other transportation methods to cars.

\subsubsection{Geely:}

When HaoQing was first introduced, the price of the car was lower than the imported counter parts: while the Daihatsu Charade, for example, cost around $\$ 15,566.25$, HaoQing only cost $\$ 3592.20$ (Qi Che Zhi Jia) [26]. Nevertheless, very little amount was sold. For one, it was not cheap enough for its targeted consumers. The annual per capita disposable income of urban areas in 1995 was around \$683.24, and farmers had much lower than that (Khan) [27]. Even if a customer was to buy HaoQing by instalments of 5 years, that was still $\$ 718.44$ a year. Furthermore, it was reported that HaoQing did not stand the rain test, its lighting had water-leakage issues, and the brakes were often failing. Even for the people who could afford HaoQing it was potentially dangerous driving it, especially when there were weather conditions.

\subsubsection{Final Consumer Preference Comparison}

ComGeely's was not as successful at capturing the preferred customer as GM did. Cars were innovations in 1900 for the Americans and thus highly demanded, and GM had specifically targeted the people who could afford cars of high quality, whereas in China, Geely targeted the people who wanted cars but at much cheaper cost, but it had failed to lower that cost, resulting very little sales of HaoQing.

\section{CONCLUSION}

The difference was almost a century, their ways to success were not only a matter of the correct decisions, but also the unique opportunities created by timings. Both companies, therefore, are shaped by the demand of the contemporary markets. After the comparison of multiple factors that influence the companies in this paper, we conclude that GM has grown to become more 
innovative in their technologies while Geely had chosen to sacrifice itself for cheaper cost, but both had ultimately captured the interests of their consumers, expanding wisely and reshaping versatilely from the changing market.

\section{REFERENCES}

[1]. Vaughan, Daniel. "1912 Cadillac Model 30." Conceptcarz.com. Dec. 2020. Web. 19 July 2021.

[2]. TSIEN, MATT. "100 Years of R\&amp;D Innovation: General Motors." 100 Years of R\&amp;D Innovation | General Motors. Web.

[3]. Maielli, Giuliano, and Colin Haslam. "General Motors: A Financialized Account of Corporate Behaviour 1909-1940." Accounting Forum 40.4 (2016): 251-64. Print.

[4]. Woods, Thomas. "The Forgotten Depression of 1920: Thomas E. Woods, Jr." Mises Institute. 15 Oct. 2009. Web. 19 July 2021.

[5]. Boss, The Pit. "The American Automotive Industry Is Packed With History." The Pit Stop Auto Blog by RumbleOn. 26 Feb. 2021. Web. 19 July 2021.

[6]. NationMaster. "Countries Compared by Economy GDP per Capita in 1900. International Statistics." NationMaster.com. NationMaster. Web. 19 July 2021.

[7]. "U.S. Automobile Production Figures." Wikipedia. Wikimedia Foundation, 04 Oct. 2020. Web. 24 Aug. 2021. James M. Flammang and the auto editors of Consumer Guide (2000). Cars of the Sensational '70s: A Decade of Changing Tastes and New Directions. Publications International, Inc. ISBN 0-7853-2980-3.

[8]. My Auto World. "A Brief History of General Motors." Brief History of General Motors. Web. 20 July 2021.

[9]. Hayward, David. "GENERAL MOTORS 1908 TO 1933." General Motors History by David Hayward. Dec. 2000. Web. 20 July 2021.

[10]. White, Darcus. "Ford Model T Suffers Dramatic Loss of Market Share after failing to Innovate." The W1nners' Club - Satirical Workplace Website and Ecommerce Store. 01 Dec. 2018. Web. 20 July 2021.

[11].Austin, Robert. "HBS Faculty Comment on the General Motors Bankruptcy." HBS Faculty Comment on the General Motors Bankruptcy News - Harvard Business School. 1 June 2009. Web. 20 July 2021.

[12].Maar, Rutger Van Der. "File:Geely Haoqing
GX9.jpg." File:Geely Haoqing GX9.jpg. 1 July 2017. Web.

[13]. "People's Republic of China." People's Republic of China - Place Explorer - Data Commons. Web. 23 July 2021.

[14].Bart DemandtCar Sales ChinaChina by BrandGeely Car SalesGeely Market Sales 2. "Geely China Sales Figures." Carsalesbase.com. 24 Mar. 2020. Web. 23 July 2021.

[15].Duoweikongjiandeqicheren.

"Renshisanliangsuanniying." Zhihuzhuanlan. 1 Apr. 2020. Web.

[16].Chan, Tony. "Geely Auto 2018 Sales Reach 1.5 Million Units, Increasing Over 20\% From Previous Year." Geely Global Media Center. 7 Jan. 2019. Web. 23 July 2021.

[17].Jun 9, 2006 - Zhejiang Geely Holding Group Co. "System for Monitoring the Tire." Justia. 9 June 2006. Web. 23 July 2021.

[18].Li, Zhigang. "Infrastructure and Urbanization in the People's Republic of China." SSRN Electronic Journal (2017). Print.

[19].De Feijter, Tycho. "Spotted In China: The Geely Liangjing JL63601E." CarNewsChina.com. 02 Dec. 2016. Web. 19 July 2021.

[20]."Highway History." U.S. Department of Transportation/Federal Highway Administration. Federal Highway Administration, 27 June 2017. Web. 23 July 2021."Highway Statistics 2014 Policy: Federal Highway Administration." U.S. Department of Transportation/Federal Highway Administration. Federal Highway Administration, 21 Mar. 2016. Web.

[21]."Total Track Mileage of Railroads for United States." ALFRED. NBER Macrohistory Database, 16 Aug. 2012. Web. 23 July 2021.

[22].Chen, James. "Understanding Antitrust Laws." Investopedia. Investopedia, 29 May 2021. Web. 26 Aug. 2021.

[23].Harwit, Eric. "The Impact of WTO Membership on the Automobile Industry in China." The China Quarterly 167 (2001). Print.

[24].Ma, Kai. "Automobile Industry Development Policy 2004." Automobile Industry Development Policy 2004 -- Souhu Finance. 2 June 2004. Web.

[25]."Geely Russia." Geely's History - the Road to Success. Web. 22 July 2021.

[26].Qi Che Zhi Jia. "Revieing Chinese Brand Growth A short history of Geely car's development." 
Revieing Chinese Brand Growth - A short history of Geely car's development_Qi Che Zhi Jiia. 18 Dec. 2020. Web. 20 July 2021. <https://chejiahao.autohome.com.cn/info/7569311\# pvareaid $=28086821202>$.

[27].Khan, Azizur Rahman, and Carl Riskin. "Income and Inequality in China: Composition, Distribution and Growth of Household Income, 1988 to 1995." The China Quarterly 154 (1998): 221-53. Print. 